\title{
Exploring the Delay in the Informed Consent \\ Procedures of Patients with ST-Elevation Myocardial Infarction Undergoing Percutaneous Coronary Intervention: Is It Worth the Wait?
}

\author{
Mailikezhati Maimaitiming \\ Peking University \\ Junxiong Ma \\ Peking University \\ Xuejie Dong \\ Peking University \\ Shuduo Zhou \\ Peking University \\ $\mathrm{Na} \mathrm{Li}$ \\ Peking University \\ Yinzi Jin ( $\nabla$ yzjin@bjmu.edu.cn ) \\ Peking University \\ Zhi-Jie Zheng \\ Peking University
}

\section{Research Article}

Keywords: informed consent delay, ST-elevation myocardial infarction, percutaneous coronary intervention, door-to-balloon time, in-hospital mortality

Posted Date: August 20th, 2021

DOl: https://doi.org/10.21203/rs.3.rs-813890/v1

License: (9) This work is licensed under a Creative Commons Attribution 4.0 International License. Read Full License 


\section{Abstract \\ Background}

Failure to achieve timely informed consent is the most important predictors of prolonged in-hospital delay in China. It is critically serious among patients with ST-elevation myocardial infarction (STEMI), which is the deadliest and most time-sensitive acute cardiac event. Informed consent procedure always begins on ambulance before door still does not complete yet after the catheterization laboratory is ready for percutaneous coronary intervention (PCl), which results in delayed treatment and poor clinical outcomes. This study aimed to investigate the factors associated with informed consent delay in patients with STEMI undergoing $\mathrm{PCl}$, and its influence on in-hospital mortality.

\section{Methods}

We conducted a national-representative retrospective cohort study, drawing patient data reported by hospital-based chest pain centers, of admission between January 2016 and June 2019. Using generalized linear mixed models and negative binomial regression, we estimated factors independently predicting informed consent delay time. The associations of informed consent delay time, door-to-balloon (D2B) time and in-hospital mortality were analyzed by logistic regression, adjusted for patient characteristics.

\section{Results}

A total of 263,219 patients were enrolled in the analysis. Informed consent delay occurred in $44.7 \%$ $(117,672)$ patients, of whom the median delayed time was 18.6 minutes $(S D=22.2)$. Patients with sustainable chest pain (RR: 1.032, $p=0.010$ ), intermittent chest pain (RR: $1.083, p<0.001$ ), and dyspnea (RR: $1.096, p=0.001$ ) were more likely to delay informed consent. Among transfer modes, walk-in (RR: $1.165, p<0.001$ ), transfer-in (RR: 1.122, $p<0.001$ ), in-hospital onset (RR: $1.248, p<0.001$ ) significantly correlated with extended informed consent delay time. The age of 35-64 years (RR: 0.941, $p=0.010$ ) had a negative association with informed consent delay time. Informed consent delay was significantly associated with prolonged D2B time (OR: 1.148, p < 0.001), whereas there was no significant association between informed consent delay and in-hospital mortality.

\section{Conclusion}

Informed consent delay provokes prolongation of door-to-balloon time, which contributes to in-hospital delay that endangers STEMI patients. For better management of STEMI patients in emergent situations, it is essential to reduce the time of informed consent obtaining through effective patient-physician communication, and care coordination within and between hospitals. 


\section{Trial registration:}

Retrospectively registered.

\section{Introduction}

ST-elevation myocardial infarction (STEMI) is the deadliest cardiovascular event that accounts for an estimated $50 \%$ of ischemic heart disease, which is the second leading cause in China. ${ }^{1}$ According to the clinical guideline, ${ }^{2}$ percutaneous coronary intervention $(\mathrm{PCl})$ is optimal treatment for STEMI whose effect mostly correlates with onset-to-treatment time, and the in-hospital delay measured by door-to-balloon (D2B) is recommended to be controlled within 90 minutes. $^{3-5}$ The latest estimated national rates of hospital admission for STEMI per 100000 population increased from 3.7 in 2001 to 15.8 in 2011; mortality from STEMI more than doubling during the past three decades, and the trend is predicted to accelerate, imposing a surging burden on individuals, communities, and health system. ${ }^{6}$ On the basis of our prior study, ${ }^{7}$ the time from onset to $\mathrm{PCl}$ is approximately 291 minutes, and $\mathrm{D} 2 \mathrm{~B}$ time accounts for the majority of treatment delay in China, ${ }^{8,9}$ and only $7 \%$ of patients receive timely $\mathrm{PCl}$ therapy.' There is a unique phenomenon in China that failure to achieve timely informed consent is the most important predictors of prolonged in-hospital delay, especially with the optimization delivery of routine clinical care for STEMI and standardization establishment of accredited chest pain centers. $9,10,11$

Undoubtedly, informed consent is indispensable for well-organized medical practice. According to laws and regulations, clinicians have to obtain patients' or relatives' consent before performing any surgery, regardless of the severity and urgency of the disease. ${ }^{11,12}$ Even though reducing in-hospital delay is of the essence, given patients' disease severity, patients' education level, the need to have a discussion with their family, it is definitely appropriate to take time to get consent from patients. ${ }^{13,14}$ Different from a usual medical treatment, a decision must be made urgently in emergency care to improve the effect of medical treatment for the patients who is in a critical situation. According to Code of Federal Regulations of America, clinicians may provide necessary medical care in emergency situations without the express consent of the patient when the patient is incapacitated or waiting to obtain consent would increase the hazard to the life or health of the patient. Same regulation also could be found in other countries, such as the United Kingdom. ${ }^{15}$

However, Chinese practitioners have the right of emergency treatment, ${ }^{12}$ but there are no clear instructions on under what circumstance it could be exerted. They commonly do not start the surgical procedure unless the patients or their relatives reach an agreement. In many situations, obtaining consent time in China is rather long that the prolongation leads to longer in-hospital delay, and further makes negative impacts on patients' clinical outcomes. This phenomenon is critically serious among patients with STEMI, which is the most time-sensitive acute cardiac event. According to the standardized diagnosis and treatment process, STEMI patients transported by emergency medical services should take the electrocardiograph on ambulance which can be transferred to ED in hospital, and coronary care unit 
should make a preliminary diagnosis rapidly based on the results of electrocardiograph and maintain real-time communication with ambulance. Thus, informed consent procedure always begins on ambulance before door. But in China, patients and their families always spend a long time in familiarizing with the severity of disease condition and understanding the treatment therapy, and they are unable to establish trust with health care professionals in a short time, resulting in long delays for the informed consent signature. In fact, informed consent procedure still does not complete yet after the catheterization laboratory is activated and ready for $\mathrm{PCl}$, which results in the prolong of in-hospital delay. Nevertheless, the delay in the informed consent procedures is modifiable, and reducing the interval for informed consent obtaining requires an understanding of modifiable factors.

It is observed that previous studies mainly focused on the whole timeline of in-hospital delay and factors related to long door-to-balloon time. ${ }^{5,16}$ Although there are researches that investigated the process of informed consent, the majority of them qualitatively explored the approaches to improving it, ${ }^{17-20}$ and other qualitative research examined informed consent obtaining during a clinical trial instead of surgery. ${ }^{21,22}$ Furthermore, to our knowledge, in countries like China where it is strictly required to obtain consent prior to emergent surgery, there are scant studies conducted to probe causes of delay in the informed consent obtaining and associated in-hospital mortality.

This study aimed to investigate the factors about the delay in informed consent procedure of STEMI patients undergoing $\mathrm{PCl}$, and its influence on in-hospital mortality, drawing on national survey data from the China Chest Pain Center Database. In evaluating the involved factors, it was believed that this study could display some underlying information that has not been reported in terms of the improvement of STEMI treatment delay in China.

\section{Methods}

\section{Data collection and participants}

Data for this retrospective cohort study were extracted from the China Chest Pain Center Database (http://data.chinacpc.org/), which is a nationwide web-based unified database that collects data of patients discharged from the hospital-based chest pain centers. As of June 30, 2019, overall 919 hospitals had accredited chest pain centers across 31 provinces. The data elements include patient demographics, prehospital treatment, presenting features, in-hospital medication and reperfusion practice, clinical outcomes and discharge. Data received are uploaded in the database in real time so that improvement in compliance to data reporting could be achieved timely. The China Cardiovascular Association is responsible for the inspection of the national audit of chest pain centers.

Participants eligible for the study should meet the following criteria: (1) were confirmed with STEMI; (2) received the reperfusion therapy of $\mathrm{PCl}$; (3) were aged 18 years or older. Patients whose medical records had failed to report time of informed consent, catheterization, discharge diagnosis and selected influencing factors of informed consent delay were excluded. Among 2,821,654 patients who were 
consequently admitted during the data collection period from January 2016 to June 2019, 263,219 were finally included in this study.

\section{Measurement}

\section{Informed consent delay}

The primary outcome was informed consent delay. Whether the informed consent is delayed is determined by evaluating the time point of informed consent signature and portal to the catheterization laboratory, as it has been proven that quick activation of the catheterization laboratory could substantially shorten D2B time. ${ }^{23}$ It was regarded as informed consent delay when catheterization activation was later than informed consent obtaining. The informed consent delay time was defined as the interval between starting informed consent and finishing the signature.

\section{In-hospital mortality}

The second outcome was the in-hospital mortality, which was calculated, according to patients' medical records, as the percentage of cases discharged as death.

\section{Factors associated with informed consent delay}

The main variables which were assumed that had an association with the informed consent delay time include: (1) patient demographics: sex, age; (2) symptoms at presentation: sustainable chest pain, intermittent chest pain, dyspnea, cardiogenic shock, heart failure, malignant arrhythmia, cardiac arrest; (3) vital signs: heart rate, Killip class (classified as classes I, II, III, and IV for measuring the least, less, more, and most severity of symptoms); (4) transport modes (classified as transported by emergency medical services (EMS), walk-in, in-hospital onset, transferred-in).

\section{Covariates for in-hospital mortality}

For analyzing the association between the informed consent delay time and in-hospital mortality, covariates included prehospital delay, patient demographics (sex, age), symptoms at presentation (sustainable chest pain, intermittent chest pain, dyspnea, cardiogenic shock, heart failure, malignant arrhythmia, cardiac arrest), vital signs (arrhythmia, Killip class), and transport modes.

\section{Statistical analysis}

Continuous variables were expressed as mean values and standard deviation (SD), whereas categorical variables were presented as frequency ( $n$ ) and percentage rate (\%). Differences in the distribution of characteristics in the patients were examined employing the T-test for continuous variables, while Chisquare test was utilized for the categorical variables. To account for clustering of patients within hospitals, we employed generalized linear mixed models with a random effect term for hospitals to 
examine participant-related factors independently contributing to the informed consent delay time. A negative binomial regression analysis was performed for the informed consent delay time if the informed consent is delayed and the effect estimates were reported as relative ratios (RRs) and $95 \% \mathrm{Cl}$. To investigate the association between the informed consent delay time and in-hospital mortality, the effect estimates were calculated from logistic regression and reported as odds ratios (ORs) and $95 \% \mathrm{Cl}$. All statistical calculations were performed using R software (R Foundation for Statistical Computing, Vienna, Austria, and Version 3.6.3). $P$ value $<0.05$ was set as statistical significance.

\section{Result}

\section{Participants characteristics}

A total of 263,219 participants were finally enrolled in the study, of which $78.6 \%(206,935)$ were male. The mean age of patients was $61.6(S D=12.4)$, with $56.2 \%$ of them being from 35 to 64 years of age. Among all patients, the median informed consent time was 7.0 minutes $(S D=19.3)$. Patient characteristics were listed in Table 1. In all symptoms at presentation, the most frequent one was sustainable chest pain (80.6\%). Of the patients, $76.9 \%$ had abnormal heart rate, and Killip class $\otimes$ was defined in $83.7 \%$ patients. As for transport modes, more than half of the participants (51.5\%) walked into the hospital, whereas only $1.9 \%$ had onset at hospital. 
Table 1

Participants characteristics

\begin{tabular}{|c|c|c|c|c|c|}
\hline Characteristics & $N(\%)$ & $\begin{array}{l}\text { Whether informed } \\
\text { consent is delayed, } n \\
(\%)\end{array}$ & $P$ & $\begin{array}{l}\text { Informed consent delay } \\
\text { time, minutes mean (SD) }\end{array}$ & $P$ \\
\hline $\begin{array}{l}\text { Admissions } \\
\text { for STEMI }\end{array}$ & 263219 & 117672 & & $18.6(22.2)$ & - \\
\hline Sex & & & $<.001$ & & $\begin{array}{l}< \\
0.001\end{array}$ \\
\hline Male & $\begin{array}{l}206935 \\
(78.6)\end{array}$ & 91885 (44.4) & & $14.2(19.2)$ & \\
\hline Female & $\begin{array}{l}56238 \\
(21.4)\end{array}$ & $25766(45.8)$ & & $14.8(19.7)$ & \\
\hline Age (years) * & & & 0.377 & & <. \\
\hline $18-34$ & $\begin{array}{l}3882 \\
(1.50)\end{array}$ & $1771(45.6)$ & & $14.9(19.7)$ & \\
\hline $35-64$ & $\begin{array}{l}147809 \\
(56.2)\end{array}$ & $66156(44.8)$ & & $14.1(19.0)$ & \\
\hline $65+$ & $\begin{array}{l}111528 \\
(42.4)\end{array}$ & $49745(44.6)$ & & 14.7 (19.7) & \\
\hline \multicolumn{6}{|l|}{$\begin{array}{l}\text { Symptoms at } \\
\text { presentation }\end{array}$} \\
\hline $\begin{array}{l}\text { Sustainable } \\
\text { chest pain }\end{array}$ & & & $<.001$ & & $\dot{0}_{0.001}$ \\
\hline No & $\begin{array}{l}50965 \\
(19.4)\end{array}$ & 22577 (44.3) & & $14.3(19.2)$ & \\
\hline Yes & $\begin{array}{l}212254 \\
(80.6)\end{array}$ & $98274(46.3)$ & & $14.6(19.9)$ & \\
\hline $\begin{array}{l}\text { Intermittent } \\
\text { chest pain }\end{array}$ & & & $<0.001$ & & $<.001$ \\
\hline No & $\begin{array}{l}226739 \\
(86.1)\end{array}$ & 100798 (44.5) & & $14.2(19.1)$ & \\
\hline Yes & $\begin{array}{l}36480 \\
(13.9)\end{array}$ & $16874(46.3)$ & & $15.0(20.5)$ & \\
\hline Dyspnea & & & 0.041 & & $<.001$ \\
\hline
\end{tabular}

* mean (SD) 


\begin{tabular}{|c|c|c|c|c|c|}
\hline Characteristics & $\mathrm{N}(\%)$ & $\begin{array}{l}\text { Whether informed } \\
\text { consent is delayed, } n \\
\text { (\%) }\end{array}$ & $P$ & $\begin{array}{l}\text { Informed consent delay } \\
\text { time, minutes mean (SD) }\end{array}$ & $P$ \\
\hline No & $\begin{array}{l}260373 \\
(98.9)\end{array}$ & 111439 (42.8) & & $14.3(19.3)$ & \\
\hline Yes & $\begin{array}{l}2846 \\
(1.1)\end{array}$ & $1272(44.7)$ & & $15.9(21.1)$ & \\
\hline $\begin{array}{l}\text { Cardiogenic } \\
\text { Shock }\end{array}$ & & & 0.004 & & 0.126 \\
\hline No & $\begin{array}{l}260309 \\
(98.9)\end{array}$ & 116449 (44.7) & & $14.3(19.3)$ & \\
\hline Yes & $\begin{array}{l}2910 \\
(1.1)\end{array}$ & $1223(42.0)$ & & $14.9(19.0)$ & \\
\hline Heart failure & & & $<0.001$ & & 0.001 \\
\hline No & $\begin{array}{l}261846 \\
(99.5)\end{array}$ & $117123(44.7)$ & & $14.3(19.3)$ & \\
\hline Yes & $\begin{array}{l}1373 \\
(0.5)\end{array}$ & $549(40.0)$ & & $16.24(21.0)$ & \\
\hline $\begin{array}{l}\text { Malignant } \\
\text { arrhythmia }\end{array}$ & & & $<.001$ & & 0.012 \\
\hline No & $\begin{array}{l}260780 \\
(99.1)\end{array}$ & $116680(44.7)$ & & $14.3(19.3)$ & \\
\hline Yes & $\begin{array}{l}2439 \\
(0.9)\end{array}$ & $992(40.7)$ & & $15.7(20.0)$ & \\
\hline Cardiac arrest & & & $<.001$ & & 0.202 \\
\hline No & $\begin{array}{l}261851 \\
(99.5)\end{array}$ & 117127 (44.7) & & $14.3(19.3)$ & \\
\hline Yes & $\begin{array}{l}1368 \\
(0.5)\end{array}$ & $545(39.8)$ & & $15.1(21.3)$ & \\
\hline \multicolumn{6}{|l|}{ Vital signs } \\
\hline $\begin{array}{l}\text { Heart rate } \\
\text { (beats/min) * }\end{array}$ & & & $<0.001$ & & 0.008 \\
\hline $60-100$ & $\begin{array}{l}58224 \\
(23.1)\end{array}$ & $26600(45.7)$ & & $14.5(19.2)$ & \\
\hline$<60$ or $>100$ & $\begin{array}{l}194236 \\
(76.9)\end{array}$ & $86662(44.6)$ & & $14.3(19.3)$ & \\
\hline * mean (SD) & & & & & \\
\hline
\end{tabular}




\begin{tabular}{|c|c|c|c|c|c|}
\hline Characteristics & $\mathbf{N}(\%)$ & $\begin{array}{l}\text { Whether informed } \\
\text { consent is delayed, } n \\
(\%)\end{array}$ & $P$ & $\begin{array}{l}\text { Informed consent delay } \\
\text { time, minutes mean (SD) }\end{array}$ & $P$ \\
\hline Killip class & & & $<001$ & & 0.027 \\
\hline$\square$ & $\begin{array}{l}194987 \\
(83.7)\end{array}$ & $88321(45.3)$ & & $14.4(19.3)$ & \\
\hline$\square$ & $\begin{array}{l}24114 \\
(10.4)\end{array}$ & 10594 (43.9) & & $14.7(20.8)$ & \\
\hline ૧ & $\begin{array}{l}4560 \\
(2.0)\end{array}$ & 1900 (41.7) & & $15.1(20.8)$ & \\
\hline$\square$ & $\begin{array}{l}9201 \\
(4.0)\end{array}$ & 3938 (42.8) & & $14.4(19.1)$ & \\
\hline $\begin{array}{l}\text { Transport } \\
\text { modes }\end{array}$ & & & $<.001$ & & $<0.001$ \\
\hline EMS & $\begin{array}{l}34548 \\
(13.1)\end{array}$ & $15565(45.1)$ & & $12.9(17.2)$ & \\
\hline $\begin{array}{l}\text { In-hospital } \\
\text { onset }\end{array}$ & $\begin{array}{l}5006 \\
(1.9)\end{array}$ & 2507 (50.1) & & $16.1(20.8)$ & \\
\hline Transfer-in & $\begin{array}{l}87971 \\
(33.4)\end{array}$ & $33116(37.6)$ & & $14.1(20.5)$ & \\
\hline Walk-in & $\begin{array}{l}135608 \\
(51.5)\end{array}$ & $66453(49.0)$ & & $14.8(19.0)$ & \\
\hline * mean (SD) & & & & & \\
\hline
\end{tabular}

As shown, $44.7 \%(117,672)$ of participants delayed informed consent, of whom the median delayed time was 18.6 minutes $(S D=22.2)$. Compared with the participants who had no chest pain or dyspnea, participants with sustainable chest pain (14.6 minutes), participants with intermittent chest pain (15.0 minutes) and participants with dyspnea (15.9 minutes) had longer median informed consent delay time, which all were positively associated with informed consent delay. On the contrary, participants who respectively had cardiogenic shock ( $42.0 \%$ vs. $44.7 \%)$, heart failure ( $40.0 \%$ vs. $44.7 \%)$, malignant arrhythmia ( $40.7 \%$ vs. $44.7 \%)$, cardiac arrest ( $39.8 \%$ vs. $44.7 \%$ ) had lower proportions in the informed consent delay. However, once these patients postponed informed consent, the delay times were longer than the patients who had not these symptoms (14.9 vs. 14.3 minutes; 16.24 vs. 14.3 minutes; 15.7 vs. 14.3 minutes; 15.1 vs. 14.3 minutes) (Table 1 ).

\section{Predictors Of Informed Consent Delay}


Results of factors that independently contributed to informed consent delay were shown in Table 2. In all symptoms at presentation, sustainable chest pain (RR: 1.032, 95\% Cl: 1.008-1.056, $p=0.010$ ), intermittent chest pain (RR: $1.083,95 \% \mathrm{Cl}: 1.057-1.110, \mathrm{p}<0.001)$, and dyspnea ((RR: $1.096,95 \% \mathrm{Cl}$ : $1.038-1.158, p=0.001$ ) were positively associated with informed consent delay time, whereas similar associations were not significant for cardiogenic shock (RR: $1.033,95 \% \mathrm{Cl}: 0.976-1.095, p=0.265$ ), heart failure (RR: $1.058,95 \% \mathrm{Cl}: 0.979-1.146, p=0.158)$, malignant arrythmia (RR: 1.057, 95\% Cl: 0.994-1.125, $\mathrm{p}=0.079$ ), and cardiac arrest (RR: $1.018,95 \% \mathrm{Cl}: 0.936-1.110, \mathrm{p}=0.675)$. As for transport modes, inhospital onset (RR: 1.248, 95\% Cl: 1.195-1.305, p< 0.001), transfer-in (RR: 1.122, 95\% Cl: 1.101-1.142, p < 0.001), walk-in (RR: 1.165, 95\% Cl: 1.144-1.185, p < 0.001) all had positive correlations with informed consent delay time. In addition, patients aged $35-64$ years (RR: $0.941,95 \% \mathrm{Cl}: 0.897-0.985, \mathrm{p}=0.010$ ) had a negative association with informed consent delay time. 
Table 2

Negative binomial regression analysis predicting informed consent delay time

\begin{tabular}{|c|c|c|c|}
\hline & RR & $95 \% \mathrm{Cl}$ & $P$ \\
\hline Sex (reference: Male) & 1.015 & {$[1.001,1.030]$} & 0.059 \\
\hline \multicolumn{4}{|l|}{ Age (reference: 18-34) } \\
\hline $35-64$ & 0.941 & {$[0.897,0.985]$} & 0.010 \\
\hline$>=65$ & 0.973 & {$[0.928,1.020]$} & 0.263 \\
\hline \multicolumn{4}{|l|}{ Symptoms at presentation } \\
\hline Sustainable chest pain (reference: No) & 1.032 & {$[1.008,1.056]$} & 0.010 \\
\hline Intermittent chest pain (reference: No) & 1.083 & {$[1.057,1.110]$} & $<0.001$ \\
\hline Dyspnea (reference: No) & 1.096 & {$[1.038,1.158]$} & 0.001 \\
\hline Cardiogenic Shock (reference: No) & 1.033 & {$[0.976,1.095]$} & 0.265 \\
\hline Heart failure (reference: No) & 1.058 & {$[0.979,1.146]$} & 0.158 \\
\hline Malignant arrhythmia (reference: No) & 1.057 & {$[0.994,1.125]$} & 0.079 \\
\hline Cardiac arrest (reference: No) & 1.018 & {$[0.936,1.110]$} & 0.675 \\
\hline Heart rate (reference: $<60$ or $>100$ ) & 0.980 & {$[0.967,0.994]$} & 0.004 \\
\hline \multicolumn{4}{|l|}{ Killip class (reference: $\rrbracket$ ) } \\
\hline प & 1.011 & {$[0.993,1.030]$} & 0.246 \\
\hline प & 1.034 & {$[0.992,1.076]$} & 0.114 \\
\hline प & 0.993 & {$[0.962,1.024]$} & 0.648 \\
\hline \multicolumn{4}{|l|}{ Transport modes (reference: EMS) } \\
\hline In-hospital onset & 1.248 & {$[1.195,1.305]$} & $<0.001$ \\
\hline Transfer-in & 1.122 & {$[1.101,1.142]$} & $<0.001$ \\
\hline Walk-in & 1.165 & {$[1.144,1.185]$} & $<0.001$ \\
\hline
\end{tabular}

Figure 1 presented the distribution of $\mathrm{D} 2 \mathrm{~B}$ time with informed consent delay time. Amongst patients whose informed consent delay time was 15-20 minutes and longer than 20.0 minutes, respectively, D2B time was prolonged from 83.2 minutes to 99.7 minutes. As shown, a small increase in informed consent delay time showed a considerable extension in D2B time when the former was longer than 20.0 minutes. 


\section{Influence Of Informed Consent Delay On In-hospital Mortality}

When informed consent was postponed, D2B time was lengthened by 12.7 minutes ( 75.1 vs. 87.8 minutes, $p<0.001)$. However, in-hospital mortality was not significantly different by informed consent delay $(p=0.377)($ Table 3$)$.

Table 3

Informed consent delay, and door-to-balloon time and in-hospital mortality

\begin{tabular}{|llll|}
\hline & $\begin{array}{l}\text { Informed consent is in- } \\
\text { time }\end{array}$ & $\begin{array}{l}\text { Informed consent is } \\
\text { delayed }\end{array}$ & $P$ \\
\hline $\mathrm{N}$ & 145547 & 117672 & \\
\hline Primary outcome & & & \\
\hline $\begin{array}{l}\text { Door-to-balloon time, min Mean } \\
\text { (SD) }\end{array}$ & $75.1(38.6)$ & $87.8(41.1)$ & 0.001 \\
\hline Secondary outcome & & & 0.377 \\
\hline $\begin{array}{l}\text { In-hospital mortality, \% Mean } \\
\text { (SD) }\end{array}$ & $2.2(14.6)$ & $2.2(14.7)$ & \\
\hline
\end{tabular}

The adjusted model analysis was shown in Table 4. After controlling covariates, patients who deferred informed consent were more likely to have longer D2B time (OR: 1.148, 95\% Cl: 1.143-1.152, p<0.001), while there was no significant difference in in-hospital mortality between these patients and those who did not delay informed consent (OR: $0.990,95 \% \mathrm{Cl}$ : 0.933-1.051, $\mathrm{p}=0.751)$. An additional minute of informed consent delay was associated with $0.7 \%$ more D2B time (OR: 1.007, 95\% Cl: 1.007-1.008, p < $0.001)$.

Table 4

Association between informed consent delay, and door-to-balloon time and in-hospital mortality Door-to-balloon time * In-hospital mortality *

OR $[95 \% \mathrm{Cl}] \quad p \quad$ OR $[95 \% \mathrm{Cl}]$

$p$

Whether informed consent is delayed (reference: No)

\begin{tabular}{lllll} 
Yes & $1.148[1.143,1.152]$ & $<0.001$ & $0.990[0.933,1.051]$ & 0.751 \\
\hline Informed consent delay time & $1.007[1.007,1.008]$ & $<0.001$ & $1.000[0.998,1.001]$ & 0.893
\end{tabular}

OR, odds ratio; $95 \% \mathrm{Cl}, 95 \%$ confidence interval

* Covariates included prehospital delay, sex, age, symptoms at presentation (sustainable chest pain, intermittent chest pain, dyspnea, cardiogenic shock, heart failure, malignant arrhythmia, cardiac arrest), vital signs (arrhythmia, Killip class), and transport modes. 


\section{Discussion}

In the context of China's health system, performing a complete informed consent procedure is necessary for any emergency. ${ }^{11,12}$ However, a study that explored the factors of delay in D2B time among the Asian population showed that the failure to provide timely informed consent was one of the predictors of prolonged D2B time, which commonly occurs in China and India. ${ }^{11}$ That is because prolongation of informed consent procedure would delay the activation of catheterization laboratory, further impacting D2B time. To our knowledge, this is the first quantitative research that analyses nationally representative data to explores the factors associated with informed consent delay in patients with STEMI. The findings of our study could be worthwhile for an improvement in STEMI care.

One of our principal findings is that informed consent delay was significantly associated with the prolongation of D2B time, namely in-hospital delay. This finding is compatible with other studies. ${ }^{11,23,24}$ In our study, approximately half of the patients postponed consent, and D2B time was prolonged over 10.0 minutes when the delay occurred. Shavadia et al., point out that every 10-min delay in initiating catheterization correlates with increasing door-to-device time, ${ }^{23}$ which would make D2B time far away from the recommended time of 90 minutes. This would inevitably give rise to a longer delay of $\mathrm{PCl}$, because with the postponement of consent, patients might get worse, meaning that $\mathrm{PCl}$ needs more time. Thus, it highlights the importance of informed consent time related to pre-activation of catheterization laboratory.

In clinical practice, Chinese doctors are merely responsible for the provision of medical information, while patients are left alone to make decisions. However, due to patients' poor understanding of medical information and fragile trust in clinicians or medical institutions, patients commonly hesitate about making up their minds. ${ }^{18,25}$ Thus, it is supposed that medical workers pay attention to their communication skills and avoid medical terminology in the transfer of knowledge. Physicians' expertise, empathy, and respect for the patients may help build trust between them. ${ }^{18}$ Furthermore, clinicians should join patients in decision-making, to help patients quickly make better understand the emergency and risks, to induce patients to quickly make an optimal choice. To improve the informed consent procedure, it is advisable to give more weight to humanistic training in medical education, such as communication skills and professionalism. ${ }^{12}$

Moreover, the results suggested that sustainable chest pain, intermittent chat pain and dyspnea were significantly related to informed consent delay, which contributed to an increase in delay times. As they are non-typical symptoms of STEMI that seem not to critically endanger the patients, they might be considered less risky. Patients and their relatives, therefore, tend to spend more time in making decisions. Inversely, cardiogenic shock, heart failure, malignant arrhythmia and cardiac arrest, which are typical symptoms of STEMI, were proven to have no significant correlations with informed consent delay time. This indicates that if patients were in more serious conditions, they would less likely to delay informed consent. From the perspective of patients and their relatives, these clinical manifestations are more threatening so that there were no statistically significant differences between patients with and without 
such typical symptoms. Furthermore, it was observed that once there was a postponement among patients with these symptoms, the delay time of them is much longer than that of patients whose condition is not so critical. One reason for it is that the higher the level of emergency, the greater the risks involved in a medical intervention responding to it. Therefore, patients and their relatives need more time to evaluate the risks and give consent. There may be an urgent need for the patients to recognize the diversity of STEMI manifestations and the benefits of timely reperfusion. Regardless of the severity of the disease, early reperfusion increases treatment effectiveness. Physicians have to emphasize the timesensitive nature of STEMI therapy while providing medical information to patients or their relatives.

Compared with EMS, other transport modes significantly lengthen the informed consent delay time. As for patients who walk into hospitals, it is presumed that their condition was relatively stable or their symptoms were less typical and critical, resulting in a lower risk consciousness to the disease. ${ }^{26}$ Additionally, patients who called for an ambulance had pre-hospital communication with healthcare workers about the conditions and treatment. As a result, it takes less time to understand PCl therapy and its risks when they were in the hospitals, indicating that it would bquicker to obtain their consent. Concerning patients who were transferred into hospitals, they had gone through the process of discharge and re-admission. Such patients had already experienced a long period of early delay, high time cost and high cost of making risky decisions, ${ }^{27,28}$ which may lead to hesitations in signing informed consent. It may also be because the symptoms of these patients were more serious, once there was a delay in informed consent obtaining, the delay time is much longer, given that patients and their relatives need more time to evaluate the risks and give consent. As for patients who had onset in the hospitals, their conditions were more complex, since they might have comorbidities and complications. This required them to sign multiple informed consent forms, causing a prolongation in doctor-patient communication and slowness in signature.

Hence, to shorten the informed consent delay time amongst patients whose transport modes were walkin, transferred-in and in-hospital onset, several suggestions are offered. First, raising the risk consciousness of patients is fundamental. Clinicians should explain the information clearly in a way that patients could understand the message they acquire and allow them to realize the importance of timely reperfusion. Showing empathy is crucial to enable the patients to feel like more than just a number them, and to increase their confidence in the physicians. ${ }^{18}$ Second, strengthening collaboration among different healthcare institutions could be beneficial to omit overlapped processes for medical history taking. Once patients decide to transfer to another hospital, the transfer-out hospital should take the initiative to contact the transfer-in hospital and inform the patient's conditions. It is warranted to develop incentive mechanisms for care coordination between different healthcare institutions, ${ }^{28}$ and government support would play an important role in intensifying the care coordination within healthcare system. ${ }^{24}$ Last, enhancing cooperation among different departments of hospitals is also recommended. In this way, times spent in the repetitive collection of medical information from the patients with comorbidities and complications could be saved. 
What is noteworthy, patients aged 35-64 years were less likely to have informed consent delay than those aged 18-34 years. Owing to special social culture of China, the major consent signers are not patients but their relatives. ${ }^{11}$ Chinese value the opinions of the whole family, while it is generally difficult for family members to achieve consensus in a limited time, ${ }^{17}$ which influences the informed consent obtaining. Nevertheless, the group of 35-64 years old may be prone to having comparatively greater autonomy that make their own decisions, meaning that the time taken to reach an agreement among their families is shorter than other groups. Further research is needed to explore the differences in informed consent procedures among STEMI patients with different demographic characteristics.

In addition, the impact of informed consent delay on in-hospital mortality is not dominant, which is compatible with prior studies. ${ }^{29,30}$ However, a large number of previous studies have confirmed that D2B time is positively correlated with in-hospital mortality. $4,9,23,31$ In our study, the informed consent delay positively correlated with D2B time, which still indirectly reflects the effect of informed consent delay on in-hospital mortality to a certain extent. However, in-hospital mortality of STEMI patients depends on multiple factors, ${ }^{30,32}$ such as demographics, severity of coronary disease, medical history, technical access, postoperative complications. Thus, it is unconvincing to independently explore the association between informed consent delay and in-hospital mortality. Follow-up studies with prospective randomized studies are warranted to confirm the net effect of informed consent delay on in-hospital mortality.

Several limitations should be considered. First and foremost, as limited access to patients' information, other social-demographic factors, such as medical history, economic status, educational attainment, were not analyzed. Still though, previous qualitative studies have investigated the contribution of these elements to informed consent delay. Besides, it is believed that data available in CPC Database were utilized in maximum to predict the factors related to informed consent delay. Second, although underaged participants occupy a certain proportion and may exert an influence on the results, they were excluded from the study. The informed consent procedure of under-aged patients is rather complex as their relatives can be surrogate signers. Their condition requires a separate discussion. Last, regional differences in information disclosure, catheterization laboratory activation processes and PCI therapy and their influence on consent obtaining timing and clinical outcomes were not evaluated within our analysis. In the process of medical treatment, there are inevitably differences between accredited CPCs hospitals. Nevertheless, our study represents hospitals from multiple geographic regions, which could minimize the bias resulted from disparities, ensuring the reliability of our findings.

\section{Conclusion}

Informed consent delay provokes prolongation of D2B time, which contributes to in-hospital delay that endangers patients diagnosed with STEMI. As PCI therapy for STEMI is highly time-depending, any delays in clinical treatment can not be underestimated. It is essential to shorten the delay time caused by extended informed consent procedure, which probably can be achieved by assisting patients in quickly 
make optimal decisions with several endeavors, such as improving their understanding of the disease and medical information, reaching a determination together with the patients, and enhancing the awareness of time-urgency on reperfusion treatment. In short, grasping the best chance for operation is of primary importance to STEMI care.

\section{Abbreviations}

STEMI: ST-segment Elevation Myocardial Infarction; D2B: door-to-balloon; EMS: Emergency Medical Services; CPC: Chest pain center; SD: standard mean; Cl: Confidence Interval.

\section{Declarations}

\section{Ethics approval and consent to participate}

This project was approved by the Peking University Health Science Center Institutional Review Board (IRB00001052-21020). The methods were carried out in accordance with the guidelines of the Declaration of Helsinki. Informed consents were obtained from registered hospitals for research approval to collect data in the China Chest Pain Center Database without requiring individual patient informed consent. Patient confidentiality will be protected in the following ways: 1 ) data are de-identifiers before their use in research, and 2) the use of data for these purposes is closely overseen by the China Cardiovascular Association.

\section{Consent for publication}

Not applicable.

\section{Availability of data and materials}

The data used and/or analyzed during the study are available from the corresponding author on reasonable request.

\section{Competing interests}

The authors declare that they have no competing interests.

\section{Funding}

This study is supported by the National Natural Science Foundation of China (No. 71904004) and the Beijing Natural Science Foundation (No. 9204025). The study sponsor has no role in study design, data analysis and interpretation of data, the writing of manuscript, or the decision to submit the paper for publication.

\section{Authors' contribution}


Mailikezhati Maimaitiming: drafting the manuscript and interpretation of results. Junxiong Ma: data collection and data analysis. Xuejie Dong: chart making and interpretation of results. Shuduo Zhou and $\mathrm{Na}$ Li: critical revision of article for important intellectual content. Yinzi Jin: study concept and design, data analysis and critical revision of article for important intellectual content. Zhi-Jie Zheng: study concept and design, and critical revision of article for important intellectual content. All authors gave final approval of the version to be published.

\section{Acknowledgments}

We thank all the colleagues working for the China Chest Pain Center Database, and members from the China Cardiovascular Association who are responsible for the inspection of the national audit of China Chest Pain Centers.

\section{References}

1. National Center for cardiovascular disease. Report of cardiovascular disease in China 2020. Beijing: Encyclopedia of China Publishing House, 2020.

2. Levine GN, Bates ER, Blankenship JC, et al. 2015 ACC/AHA/SCAI Focused Update on Primary Percutaneous Coronary Intervention for Patients With ST-Elevation Myocardial Infarction: An Update of the 2011 ACCF/AHA/SCAI Guideline for Percutaneous Coronary Intervention and the 2013 ACCF/AHA Guideline for the Management of ST-Elevation Myocardial Infarction. Journal of the American College Cardiology. 2016; 67(10): 1235-1250.

3. Brodie BR, Stone GW, Cox DA, et al. Impact of treatment delays on outcomes of primary percutaneous coronary intervention for acute myocardial infarction: analysis from the CADILLAC trial. Am Heart J. 2006;151(6):1231-1238. doi:10.1016/j.ahj.2005.07.016

4. McNamara RL, Wang Y, Herrin J, et al. Effect of door-to-balloon time on mortality in patients with STsegment elevation myocardial infarction. J Am Coll Cardiol. 2006;47(11):2180-2186. doi:10.1016/j.jacc.2005.12.072

5. Beig JR, Tramboo NA, Kumar K, et al. Components and determinants of therapeutic delay in patients with acute ST-elevation myocardial infarction: A tertiary care hospital-based study. J Saudi Heart Assoc. 2017;29(1):7-14. doi:10.1016/j.jsha.2016.06.001

6. Li J, Li X, Wang Q, et al. ST-segment elevation myocardial infarction in China from 2001 to 2011 (the China PEACE-Retrospective Acute Myocardial Infarction Study): a retrospective analysis of hospital data. Lancet. 2015;385(9966):441-451. doi:10.1016/S0140-6736(14)60921-1

7. Xiang D, Jin Y, Fang W, Su X, Yu B, Wang Y, Wang W, Wang L, Yan H, Fu X, Zheng Z, Labresh KA, Huo $\mathrm{Y}, \mathrm{Ge}$ J. Monitor and Improve Quality of Care for Acute Cardiac Events in China: Designing and Implementing the National Chest Pain Centers Program. Cardiology Plus.

8. Song L, Yan HB, Yang JG, et al. Zhonghua Xin Xue Guan Bing Za Zhi. 2010;38(4):301-305. 
9. Dong S, Chu Y, Zhang H, et al. Reperfusion times of ST-Segment elevation myocardial infarction in hospitals. Pak J Med Sci. 2014;30(6):1367-1371. doi:10.12669/pjms.306.5696

10. Zhang Y, Yu B, Han Y, et al. Protocol of the China ST-segment elevation myocardial infarction (STEMI) Care Project (CSCAP): a 10-year project to improve quality of care by building up a regional STEMI care network. BMJ Open. 2019;9(7):e026362. Published 2019 Jul 17. doi:10.1136/bmjopen2018-026362

11. Li L, Wu MY, Zhang F, et al. Perspective of delay in door-to-balloon time among Asian population. $J$ Geriatr Cardiol. 2018;15(12):732-737. doi:10.11909/j.issn.1671-5411.2018.12.001

12. Gong N, Zhou Y, Cheng Y, et al. Practice of informed consent in Guangdong, China: a qualitative study from the perspective of in-hospital patients. BMJ Open. 2018;8(10):e020658. Published 2018 Oct 3. doi:10.1136/bmjopen-2017-020658

13. Hanson M, Pitt D. Informed consent for surgery: risk discussion and documentation. Can J Surg. 2017;60(1):69-70. doi:10.1503/cjs.004816

14. Mendelson SJ, Courtney DM, Gordon EJ, Thomas LF, Holl JL, Prabhakaran S. National Practice Patterns of Obtaining Informed Consent for Stroke Thrombolysis. Stroke. 2018;49(3):765-767. doi:10.1161/STROKEAHA.117.020474

15. Jeries W, Mahil J, Upile T. English law for the surgeon I: consent, capacity and competence [J]. Head Neck Oncol, 2011, 3:41.

16. Alishahi Tabriz A, Sohrabi MR, Kiapour N, Yazdani S. Factors Associated with Delay in Thrombolytic Therapy in Patients with ST-Elevation Myocardial Infarction. J Tehran Heart Cent. 2012;7(2):65-71.

17. Spertus JA, Bach R, Bethea $C$, et al. Improving the process of informed consent for percutaneous coronary intervention: patient outcomes from the Patient Risk Information Services Manager (ePRISM) study. Am Heart J. 2015;169(2):234-241.e1. doi:10.1016/j.ahj.2014.11.008

18. Convie LJ, Carson E, McCusker D, et al. The patient and clinician experience of informed consent for surgery: a systematic review of the qualitative evidence. BMC Med Ethics. 2020;21(1):58. Published 2020 Jul 11. doi:10.1186/s12910-020-00501-6

19. Spencer SP, Stoner MJ, Kelleher K, Cohen DM. Using a Multimedia Presentation to Enhance Informed Consent in a Pediatric Emergency Department. Pediatr Emerg Care. 2015;31(8):572-576. doi:10.1097/PEC.0000000000000513

20. Bellolio MF, E Silva LOJ, Puls HA, Hargraves IG, Cabrera D. The research to practice continuum: Development of an evidence-based visual aid to improve informed consent for procedural sedation. J Clin Trans/ Sci. 2017;1(5):316-319. doi:10.1017/cts.2017.303

21. Scicluna VM, Goldkind SF, Mitchell AR, et al. Determinants of Patient and Surrogate Experiences With Acute Care Research Consent: A Key Informant Interview Study. J Am Heart Assoc. 2019;8(22):e012599. doi:10.1161/JAHA.119.012599

22. Kompanje EJO, van Dijck JTJM, Chalos V, et al. Informed consent procedures for emergency interventional research in patients with traumatic brain injury and ischaemic stroke [published 
correction appears in Lancet Neurol. 2021 Apr;20(4):e3]. Lancet Neurol. 2020;19(12):1033-1042. doi:10.1016/S1474-4422(20)30276-3

23. Shavadia JS, Roe MT, Chen AY, et al. Association Between Cardiac Catheterization Laboratory PreActivation and Reperfusion Timing Metrics and Outcomes in Patients With ST-Segment Elevation Myocardial Infarction Undergoing Primary Percutaneous Coronary Intervention: A Report From the ACTION Registry. JACC Cardiovasc Interv. 2018;11(18):1837-1847. doi:10.1016/j.jcin.2018.07.020

24. Zhang Y, Tian Y, Dong P, et al. Treatment Delay and Reperfusion Management of Acute ST-segment Elevation Myocardial Infarction - analysis of the China STEMI Care Project Phase 1 (CSCAP-1) [published online ahead of print, 2020 Jun 22]. QJM. 2020;

hcaa186. doi:10.1093/qjmed/hcaa186

25. Feinstein MM, Adegboye J, Niforatos JD, Pescatore RM. Informed consent for invasive procedures in the emergency department. Am J Emerg Med. 2021;39:114-120. doi:10.1016/j.ajem.2020.01.035

26. Caltabellotta T, Magne J, Salerno B, et al. Characteristics associated with patient delay during the management of ST-segment elevated myocardial infarction, and the influence of awareness campaigns. Arch Cardiovasc Dis. 2021;114(4):305-315. doi:10.1016/j.acvd.2020.09.004

27. Wang TY, Nallamothu BK, Krumholz HM, et al. Association of door-in to door-out time with reperfusion delays and outcomes among patients transferred for primary percutaneous coronary intervention. JAMA. 2011;305(24):2540-2547. doi:10.1001/jama.2011.862

28. Spencer FA, Montalescot G, Fox KA, et al. Delay to reperfusion in patients with acute myocardial infarction presenting to acute care hospitals: an international perspective. Eur Heart $\mathrm{J}$. 2010;31(11):1328-1336. doi:10.1093/eurheartj/ehq057

29. De Luca G, Suryapranata H, Zijlstra F, et al. Symptom-onset-to-balloon time and mortality in patients with acute myocardial infarction treated by primary angioplasty. J Am Coll Cardiol. 2003;42(6):991997. doi:10.1016/s0735-1097(03)00919-7

30. Zahn R, Vogt A, Zeymer U, et al. In-hospital time to treatment of patients with acute ST elevation myocardial infarction treated with primary angioplasty: determinants and outcome. Results from the registry of percutaneous coronary interventions in acute myocardial infarction of the Arbeitsgemeinschaft Leitender Kardiologischer Krankenhausarzte. Heart. 2005;91(8):1041-1046. doi:10.1136/hrt.2004.045336

31. Bradley EH, Herrin J, Wang Y, et al. Strategies for reducing the door-to-balloon time in acute myocardial infarction. N Engl J Med. 2006;355(22):2308-2320. doi:10.1056/NEJMsa063117

32. Cenko E, Yoon J, Kedev S, et al. Sex Differences in Outcomes After STEMI: Effect Modification by Treatment Strategy and Age. JAMA Intern Med. 2018;178(5):632-639.

doi:10.1001/jamainternmed.2018.0514

\section{Figures}




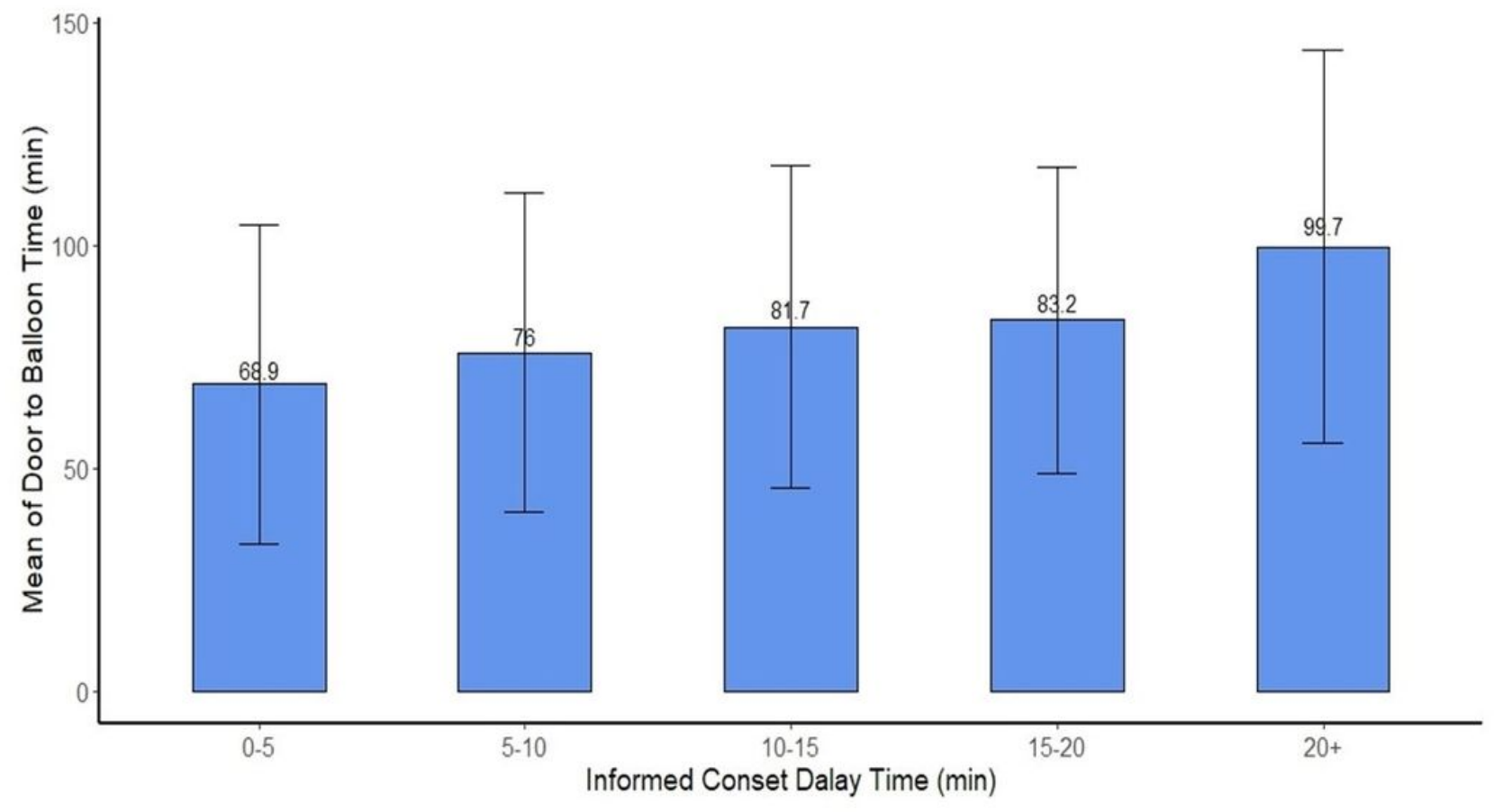

Figure 1

Distribution of Door to Balloon time with Informed consent delay time 